\title{
Thermodynamic Favorability of End Products of Anaerobic Glucose Metabolism
}

\author{
Peter J. Halling* \\ Cite This: https://dx.doi.org/10.1021/acsomega.0c00790 \\ Read Online
}

Supporting Information

\begin{abstract}
The eQuilibrator component contribution method allows calculation of the overall Gibbs energy changes for conversion of glucose to a wide range of final products in the absence of other oxidants. Values are presented for all possible combinations of products with up to three carbons and selected others. The most negative Gibbs energy change is for the formation of graphite and water $\left(-499 \mathrm{~kJ} \mathrm{~mol}^{-1}\right)$ followed by $\mathrm{CH}_{4}$ and $\mathrm{CO}_{2}(-430 \mathrm{~kJ}$ $\mathrm{mol}^{-1}$ ), the observed final products of anaerobic digestion. Other favored products (with various combinations having Gibbs energy changes between -300 and $-367 \mathrm{~kJ} \mathrm{~mol}^{-1}$ ) are short-chain alkanes, fatty acids, dicarboxylic acids, and even hexane and benzene. The most familiar products, lactate and ethanol $+\mathrm{CO}_{2}$, are less favored (Gibbs energy changes of -206 and $-265 \mathrm{~kJ} \mathrm{~mol}^{-1}$ respectively). The values presented offer an interesting perspective on observed metabolism and its evolutionary origins as well as on cells engineered for biotechnological purposes.
\end{abstract}

\section{INTRODUCTION}

There is a long history of using thermodynamic analysis to aid our understanding of metabolism. Biochemistry textbooks give standard Gibbs energy changes for reactions in core metabolic pathways based on measurements of equilibrium constants. The NIST Thermodynamics of Enzyme-Catalyzed Reactions database $^{1}$ (https://randr.nist.gov/enzyme/ DOI: 10.18434/ T40W22) collects measured equilibrium constants for biochemical reactions. From these, it is possible to calculate Gibbs energies of formation for metabolites, ${ }^{2}$ which can in turn be used to calculate Gibbs energy changes for other reactions for which there are no measurements. Methods have also been developed to give fairly accurate predictions of Gibbs energies of formation of a wide range of compounds of biochemical relevance with their chemical structure as the only input required. ${ }^{3-9}$ These methods have been exploited for thermodynamic analysis of a variety of actual and hypothetical metabolic pathways and networks. ${ }^{10-15}$ For example, it can be shown that the classic EMP glycolysis pathway is optimal for the conversion of glucose to lactate. ${ }^{16}$

Gibbs energies of formation can also be used to analyze the overall thermodynamics of transformation of nutrients into end products. The overall Gibbs energy change for this process can be calculated, independent of whatever might be the exact metabolic pathway involved. This approach has been used to assess the feasibility of formation of various end products by rumen microbes. ${ }^{17}$ It has also been applied to the possible formation of various industrial chemicals by engineered organisms. ${ }^{18}$ It is interesting to use these prediction methods to consider the choice of overall end products of sugar fermentation under anaerobic conditions (and in the absence of other oxidizing species such as nitrate or sulfate). This paper presents the overall Gibbs energy changes for conversion of glucose into all possible combinations of compounds having up to three carbon atoms and some selected larger molecules. These values have been calculated because they should be useful in analyzing the extent to which the overall Gibbs energy change has been a driver in the evolution of anaerobic metabolism. They also provide an interesting perspective on products of metabolism observed in current biochemistry. The values also highlight some options for metabolic engineering and synthetic biology, showing that some practically interesting end products are thermodynamically favored.

\section{RESULTS}

Gibbs Energies of Formation. The aim is to tabulate the overall Gibbs energy changes for the metabolism of glucose to a wide range of possible end products in the absence of additional oxidants. These changes can be calculated from estimates of the Gibbs energy of formation for glucose, water, and each possible end product. These Gibbs energies of formation were obtained using the online eQuilibrator service, ${ }^{3,4}$ which has been shown to give generally good estimates. ${ }^{7}$ There is a good argument in that basing the Gibbs energies of formation and reaction on a standard state of $1 \mathrm{mM}$ in solution is more biochemically relevant than the $1 \mathrm{M}$ choice usual in chemistry. ${ }^{3,4}$ This has been adopted in the present work, so the values presented are for

Received: February 22, 2020

Accepted: June 11, 2020 
$\Delta G_{\mathrm{f}}{ }^{\prime \mathrm{m}}$ (formation) and $\Delta G_{\mathrm{r}}{ }^{\prime \mathrm{m}}$ (reaction) using the symbols of Noor et al. ${ }^{3,4}$ for $\mathrm{pH} 7$ except where otherwise stated.

Compounds Considered. The analysis attempts to include all possible $\mathrm{C}_{1}, \mathrm{C}_{2}$, and $\mathrm{C}_{3}$ compounds containing also hydrogen and/or oxygen. Some classes were not considered in detail because they were expected to be always higher in energy: ethers, esters, cyclopropanes, oxetane, cumulenes, enols, ynols, and gem-diols (see Methods). The number of compounds that have to be considered in the final analysis can be reduced further by making some pre-selections.

Isomeric Compounds. First, some compounds are isomers of each other. By comparing the formation Gibbs energies of each isomer, the lowest energy can be selected; this is the one that has the best chance of being a favored end product. Table 1

\section{Table 1. Selection of Favored Isomers}

\begin{tabular}{|c|c|c|}
\hline $\begin{array}{l}\text { empirical } \\
\text { formula }\end{array}$ & $\begin{array}{l}\text { favored isomer (with } \\
\Delta G_{\mathrm{f}}^{\prime m} \text { in } \mathrm{kJ} \mathrm{mol}^{-1} \text { ) }\end{array}$ & $\begin{array}{l}\text { higher Gibbs energy isomers (with } \Delta \mathrm{G}_{\mathrm{f}}^{\prime \mathrm{m}} \\
\text { in } \mathrm{kJ} \mathrm{mol}^{-1} \text { ) }\end{array}$ \\
\hline $\mathrm{C}_{2} \mathrm{H}_{4} \mathrm{O}$ & ethanal (5) & ethylene oxide (29) \\
\hline $\mathrm{C}_{2} \mathrm{H}_{4} \mathrm{O}_{2}$ & acetate $(-264)$ & glycolaldehyde $\left(\mathrm{CH}_{2} \mathrm{OH} . \mathrm{CHO}\right)(-148)$ \\
\hline $\mathrm{C}_{3} \mathrm{H}_{8} \mathrm{O}$ & 2-propanol (123) & 1-propanol (131) \\
\hline $\mathrm{C}_{3} \mathrm{H}_{8} \mathrm{O}_{2}$ & $\begin{array}{l}\text { propylene glycol } \\
(-25)\end{array}$ & 1,3-propanediol $(-23)$ \\
\hline $\mathrm{C}_{3} \mathrm{H}_{6} \mathrm{O}$ & acetone (66) & $\begin{array}{l}\text { propanal (93), epoxypropane (111), allyl } \\
\text { alcohol (135) }\end{array}$ \\
\hline $\mathrm{C}_{3} \mathrm{H}_{6} \mathrm{O}_{2}$ & propanoate $(-178)$ & $\begin{array}{l}\text { hydroxyacetone }(-68) \text {, } \\
\text { 2-hydroxypropanal }(-66) \text {, } \\
\text { 3-hydroxypropanal }(-64) \text {, glycidol } \\
(-46)\end{array}$ \\
\hline $\mathrm{C}_{3} \mathrm{H}_{6} \mathrm{O}_{3}$ & $\begin{array}{l}\text { 3-hydroxypropanoate } \\
(-333)\end{array}$ & $\begin{array}{l}\text { lactate }(-326) \text {, dihydroxyacetone } \\
(-226) \text {, glyceraldehyde }(-223)\end{array}$ \\
\hline $\mathrm{C}_{3} \mathrm{H}_{4} \mathrm{O}_{2}$ & acrylate $(-165)$ & $\begin{array}{l}\text { propiolactone }(-124), \text { pyruvaldehyde } \\
(-112) \text {, malondialdehyde }(-106), \\
\text { glycidaldehyde }(-87)\end{array}$ \\
\hline $\mathrm{C}_{3} \mathrm{H}_{4} \mathrm{O}_{3}$ & $\begin{array}{l}\text { malonate } \\
\text { semialdehyde } \\
(-374)\end{array}$ & pyruvate $(-363)^{a}$ \\
\hline $\mathrm{C}_{3} \mathrm{H}_{4} \mathrm{O}_{4}$ & malonate $(-624)$ & $\begin{array}{l}\text { hydroxypyruvate }(-514), 2 \text {-hydroxy-3- } \\
\text { oxopropanoate }(-513)\end{array}$ \\
\hline
\end{tabular}

${ }^{a_{T}}$ There are several other isomers here for which eQuilibrator offers no predictions. Hydroxypyruvaldehyde $\left(\mathrm{CH}_{2} \mathrm{OH} \cdot \mathrm{CO} \cdot \mathrm{CHO}\right)$ and hydroxymalondialdehyde (OHC. $\mathrm{CHOH} \cdot \mathrm{CHO}$ ) are expected to be higher in energy than pyruvate from comparisons of isomers having a carboxyl group as opposed to separate hydroxyls and carbonyls. (Compare acetate and glycoladehyde, propanoate with hydroxypropanals, and malonate with hydroxypyruvate. This general pattern was noted by $\mathrm{Weber}^{22}$ ). Epoxypropanoate is expected to be of higher Gibbs energy than that of pyruvate based on comparisons of other epoxy versus carbonyl compounds: epoxypropane versus acetone and glycidol versus hydroxyacetone. Finally, the 4-membered ring in the lactone of glyceric acid can be thought of being opened by cleavage of the $\mathrm{CH}_{2}-\mathrm{O}$ bond giving the enol of pyruvate. The equivalent cleavage in propiolactone gives acrylate with a Gibbs energy of $41 \mathrm{~kJ} \mathrm{~mol}^{-1}$ lower.

shows the selections that can be made in this way. Some cases of isomers where predicted $\Delta G_{f}{ }^{\prime m}$ values are not available from eQuilibrator are discussed in Methods. It is interesting to note that, even though lactate is a classic product of anaerobic glycolysis, its formation is slightly less favored than 3hydroxypropanoate (whose production in engineered organisms has been studied as a possible biotechnological process ${ }^{9-21}$ ).

Compounds Inter-related by Hydration. Other compounds (or groups of isomers) have carbon in the same formal oxidation state and are interrelated by the addition or removal of elements of water. There may not be a simple hydration reaction, but in calculating the overall thermodynamics, just one compound in that oxidation state will be the lowest-Gibbs energy form. This is because we assume that the overall conversion is taking place in aqueous solution and water may be a net reactant or product in the process. Table 2 shows how this can be used to reduce the number of products to be considered in identifying the most thermodynamically favorable options. The systematically favorable dehydration of diols to give carbonyl compounds (see ethanal and acetone) was previously noted by Weber. ${ }^{22}$

Possible Overall Transformations. Along with the favored products listed in Tables 1 and 2, a number of other compounds were included that have no plausible isomers or (de)hydration forms. This led to the following complete list: $\mathrm{CO}_{2}$, formate, elemental carbon, methanol, methane, oxalate $(\mathrm{HOOC} \cdot \mathrm{COOH})$, glyoxylate $(\mathrm{OHC} \cdot \mathrm{COOH})$, hydroxyacetate (also named glycolate), acetate, ethanal, ethanol, ethane, oxomalonate (HOOC.CO.COOH), hydroxymalonate (HOOC.CHOH$\cdot \mathrm{COOH}$ ), malonate, malonate semialdehyde $\left(\mathrm{OHC} \cdot \mathrm{CH}_{2} \cdot \mathrm{COOH}\right), 3$-hydroxypropanoate, propanoate, acetone, 2-propanol, and propane. To this list were added molecular hydrogen $\mathrm{H}_{2}$ and a selection of compounds with more than three carbon atoms. Butane, butanoic acid, and succinic acid were found to be local minimum energy forms in a study of redox potentials of all possible oxidation states of a fourcarbon chain. ${ }^{23}$ Glutarate $\left(\mathrm{C}_{5} \mathrm{H}_{8} \mathrm{O}_{4}\right)$ is an interesting case of a dicarboxylic acid that has the same formal oxidation state as that of glucose. Benzene was added to explore the effect of aromatic stabilization, and hexane gives an aliphatic six-carbon comparison. Heterocyclic aromatic furan $\left(\mathrm{C}_{4} \mathrm{H}_{4} \mathrm{O}\right)$ would also be an interesting possibility, but eQuilibrator does not offer a $\Delta G_{f}{ }^{\prime m}$ prediction. Finally, citrate was added as an example tricarboxylic acid.

Some possible products have carbon in the same formal oxidation state $(0)$ as in glucose. Hence, they can be formed as a single carbon-containing product from glucose, perhaps with water as an additional reactant or product (Table 3).

Other possible transformations make two products, one more oxidized and one more reduced than glucose. The overall Gibbs energy change was calculated for every possible combination of such products from the list above. This used the unique overall stoichiometric equation that produces the two products, which may also involve water as an additional reactant or product.

It is of course possible for metabolism to produce more than two end products. However, the overall equation for such transformations can be written as the linear sum of two or more conversions that each makes just one or two carbon-containing products. Hence, the overall Gibbs energy change will be intermediate between those for the individual summed conversions. Therefore, there is no need to include these as separate possibilities to be tabulated.

Certain possible products have been removed from Table 4 presented here to make it easier to follow (a table with all possible oxidized and reduced products is available in the Supporting Information). Production of formate is somewhat worse than $\mathrm{CO}_{2}$ formation in combination with all reduced products except $\mathrm{H}_{2}$ where the overall $\Delta G_{\mathrm{r}}{ }^{\prime \mathrm{m}}$ is still only $-67 \mathrm{~kJ}$ $\mathrm{mol}^{-1}$. Production of glyoxylate always gives a less negative (worse) $\Delta G_{\mathrm{r}}{ }^{\prime m}$ than that of hydroxyacetate or oxalate in combination with the same reduced product. Similarly, production of malonate semialdehyde, hydroxymalonate, or oxomalonate is always worse than malonate in combination with the same reduced product and production of citrate is always 
Table 2. Selection of Compounds Related by (De)hydration ${ }^{a}$

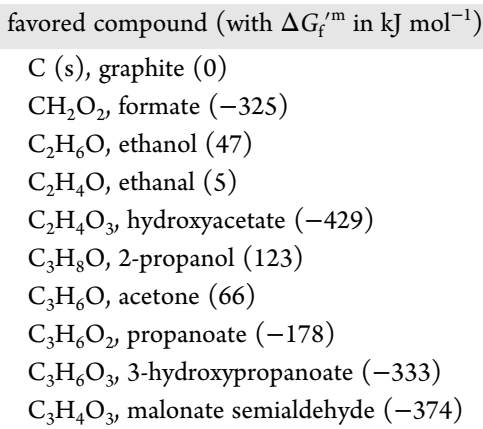

higher Gibbs energy combinations (with $\Delta G_{\mathrm{f}}^{\prime \mathrm{m}}$ in $\mathrm{kJ} \mathrm{mol}^{-1}$ )

$\mathrm{CH}_{2} \mathrm{O}$ (formaldehyde) $-\mathrm{H}_{2} \mathrm{O}$ (98)

$\mathrm{CO}+\mathrm{H}_{2} \mathrm{O}(-295)$

$\mathrm{C}_{2} \mathrm{H}_{4}$ (ethene) $+\mathrm{H}_{2} \mathrm{O}(69)$

$\mathrm{C}_{2} \mathrm{H}_{6} \mathrm{O}_{2}$ (ethylene glycol) $-\mathrm{H}_{2} \mathrm{O}$ (47)

$\mathrm{C}_{2} \mathrm{H}_{2} \mathrm{O}_{2}$ (glyoxal) $+\mathrm{H}_{2} \mathrm{O}(-351)$

$\mathrm{C}_{3} \mathrm{H}_{6}$ (propene) $+\mathrm{H}_{2} \mathrm{O}$ (134)

$\mathrm{C}_{3} \mathrm{H}_{8} \mathrm{O}_{2}$ (propylene glycol) $-\mathrm{H}_{2} \mathrm{O}(133)$

$\mathrm{C}_{3} \mathrm{H}_{4} \mathrm{O}$ (acrolein) $+\mathrm{H}_{2} \mathrm{O}(-64) ; \mathrm{C}_{3} \mathrm{H}_{8} \mathrm{O}_{3}$ (glycerol) $-\mathrm{H}_{2} \mathrm{O}$ (129)

$\mathrm{C}_{3} \mathrm{H}_{4} \mathrm{O}_{2}$ (acrylate) $+\mathrm{H}_{2} \mathrm{O}(-323)$

$\mathrm{C}_{3} \mathrm{H}_{6} \mathrm{O}_{4}$ (glycerate) $-\mathrm{H}_{2} \mathrm{O}(-325)$

${ }^{a}$ Some other possible (de)hydration reactions where eQuilibrator does not offer values of $\Delta G_{\mathrm{f}}^{\prime m}$ are discussed in the Methods.

Table 3. Single Products that Can be Produced Nonoxidatively from Glucose ${ }^{a}$

$\begin{array}{rlr} & \text { overall process } & \text { overall } \Delta G_{\mathrm{r}}{ }^{\prime m} \\ \mathrm{C}_{6} \mathrm{H}_{12} \mathrm{O}_{6} \rightarrow 6 \mathrm{C}(\mathrm{s})+6 \mathrm{H}_{2} \mathrm{O} & -499 \\ \mathrm{C}_{6} \mathrm{H}_{12} \mathrm{O}_{6} \rightarrow 3 \text { acetate } & -345 \\ \mathrm{C}_{6} \mathrm{H}_{12} \mathrm{O}_{6} \rightarrow 2 \text { 3-hydroxypropanoate } & -220 \\ \mathrm{C}_{6} \mathrm{H}_{12} \mathrm{O}_{6} \rightarrow 1.2 \text { glutarate }+1.2 \mathrm{H}_{2} \mathrm{O} & -279\end{array}$

${ }^{a}$ Note that three of these have been pre-selected as favored products compared with possible isomers (Table 1) or hydration/dehydration linked compounds (Table 2). Examples are $\mathrm{C}\left(\mathrm{s}\right.$ ) over $\mathrm{CH}_{2} \mathrm{O}$, acetate over glycolaldehyde, and 3-hydroxypropanoate over lactate, dihydroxyacetone, and acrylate.

Table 4. Overall Gibbs Energy Changes for Metabolism of Glucose to One More Reduced and One More Oxidized Product $^{a}$

\begin{tabular}{|c|c|c|c|c|c|c|}
\hline \multirow{2}{*}{\multicolumn{2}{|c|}{$\begin{array}{l}\text { Values are } \Delta \mathrm{G}_{\mathrm{r}}{ }^{\prime}{ }^{\mathrm{m}} \text { in } \\
\mathrm{kJ} \mathrm{mol}^{-1} \text {. }\end{array}$}} & \multicolumn{5}{|c|}{ Oxidized product } \\
\hline & & $\mathrm{CO}_{2}$ & hydroxyacetate & oxalate & malonate & succinate \\
\hline \multirow{13}{*}{ 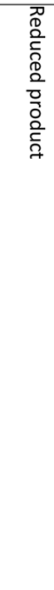 } & $\mathrm{H}_{2}$ & -47 & -122 & 47 & -159 & -235 \\
\hline & $\mathrm{CH}_{4}$ & -430 & -260 & -322 & -323 & -299 \\
\hline & methanol & -165 & -156 & -116 & -185 & -232 \\
\hline & ethane & -367 & -243 & -280 & -297 & -288 \\
\hline & ethanol & -265 & -206 & -206 & -245 & -262 \\
\hline & propane & -350 & -239 & -270 & -290 & -285 \\
\hline & 2-propanol & -301 & \begin{tabular}{|l|}
-224 \\
\end{tabular} & -238 & -267 & -273 \\
\hline & acetone & -295 & -232 & -247 & -269 & -274 \\
\hline & propanoate & -339 & -281 & -308 & -311 & -300 \\
\hline & butanoate & -330 & -261 & -289 & -297 & -290 \\
\hline & butane & -343 & \begin{tabular}{|l|}
-238 \\
\end{tabular} & -267 & -288 & -284 \\
\hline & benzene & -329 & -260 & -288 & -296 & -289 \\
\hline & hexane & -342 & -240 & -269 & -288 & -284 \\
\hline
\end{tabular}

${ }^{a}$ Progressively darker shading highlights values in the ranges of -250 to $-300 \mathrm{~kJ} \mathrm{~mol}^{-1},-300$ to $-350 \mathrm{~kJ} \mathrm{~mol}^{-1},-350$ to $-400 \mathrm{~kJ} \mathrm{~mol}^{-1}$, and values more negative than $-400 \mathrm{~kJ} \mathrm{~mol}^{-1}$.

worse than succinate in combination with the same reduced product. Finally, the formation of ethanal is always less favorable than producing ethanol in combination with the same oxidized product.

Effect of $\mathrm{pH}$. The overall Gibbs energy changes presented so far are for $\mathrm{pH} 7$, but most will depend significantly on the $\mathrm{pH}$. Most of the overall transformations produce one or more acidic products, so the $\Delta G_{\mathrm{r}}{ }^{\mathrm{m}}$ values will become more favorable (negative) as the $\mathrm{pH}$ rises. The size of the effect depends on the number of $\mathrm{H}^{+}$released in the overall reaction equation. The biggest dependencies would be for the formation of six formate or three oxalate compounds in combination with $\mathrm{H}_{2}$, although neither of these are very favored conversions at $\mathrm{pH}$ 7. At the other extremes, there are product combinations like 0.5 benzene and 1.5 glyoxal that have no acidic products at all, although again, with a $\Delta G_{\mathrm{r}}{ }^{\prime \mathrm{m}}$ of only $-143 \mathrm{~kJ} \mathrm{~mol}^{-1}$, this is not particularly favored. For some intermediate cases, differences in $\mathrm{pH}$ dependency can change the ordering of possible product combinations. Figure 1 shows examples of the formation of

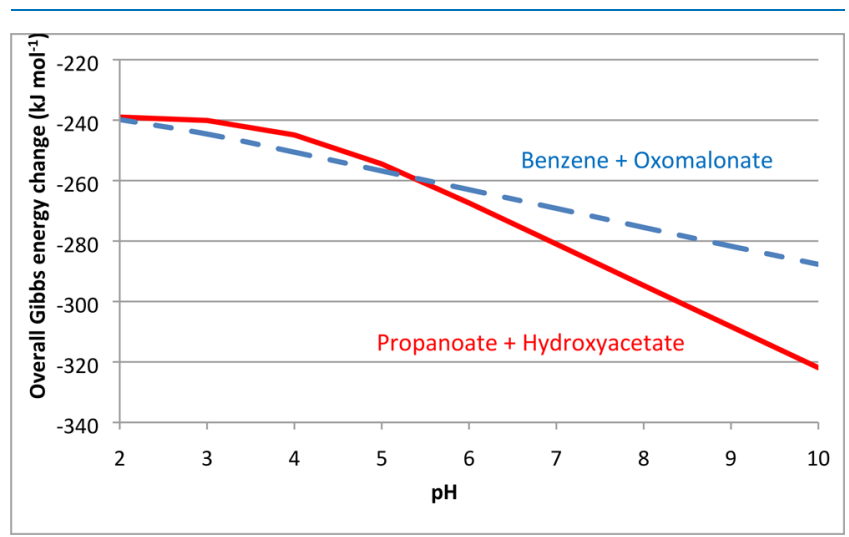

Figure 1. Examples of the $\mathrm{pH}$ effect on overall Gibbs energy change. These are overall $\Delta G_{\mathrm{r}}{ }^{\prime m}$ values calculated by eQuilibrator for the conversions $\mathrm{C}_{6} \mathrm{H}_{12} \mathrm{O}_{6}=8 / 11 \mathrm{C}_{6} \mathrm{H}_{6}+6 / 11 \mathrm{C}_{3} \mathrm{H}_{2} \mathrm{O}_{5}$ (oxomalonate) + $36 / 11 \mathrm{H}_{2} \mathrm{O}$ and $\mathrm{C}_{6} \mathrm{H}_{12} \mathrm{O}_{6}=1.2 \mathrm{C}_{3} \mathrm{H}_{6} \mathrm{O}_{2}$ (propanoate) $+1.2 \mathrm{C}_{2} \mathrm{H}_{4} \mathrm{O}_{3}$ (hydroxyacetate).

$8 / 11$ benzene and 6/11 oxomalonate, hence just over $1 \mathrm{H}^{+}$per glucose, compared with 1.2 propanoate and 1.2 hydroxyacetate, so approximately $2.4 \mathrm{H}^{+}$per glucose. The latter has a more negative $\Delta G_{\mathrm{r}}{ }^{\prime \mathrm{m}}$ at $\mathrm{pH} 7$, but in acid, the former becomes more favored because of its lower $\mathrm{pH}$ dependence.

Effect of Product Concentrations and Ease of Product Removal. The calculations so far have been made on the basis that all products accumulate to a concentration of $1 \mathrm{mM}$. If we consider instead the conversion of $1 \mathrm{M}$ glucose to $1 \mathrm{M}$ products, the Gibbs energy change $\left(\Delta G_{\mathrm{r}}{ }^{\prime}\right)$ will be less favorable where more than one molecule of products (other than $\mathrm{H}_{2} \mathrm{O}$ ) are formed from one molecule of glucose. Therefore, for the conversion glucose $\rightarrow 0.5$ benzene +0.5 citrate $+2.5 \mathrm{H}_{2} \mathrm{O}, \Delta G_{\mathrm{r}}{ }^{\prime \mathrm{m}}$ and $\Delta G_{\mathrm{r}}{ }^{\prime 0}$ are exactly equal at $-267 \mathrm{~kJ} \mathrm{~mol}^{-1}$. However, for glucose $\rightarrow 3 \mathrm{CH}_{4}+3 \mathrm{CO}_{2}, \Delta G_{\mathrm{r}}{ }^{\prime \mathrm{m}}$ is $-430 \mathrm{~kJ} \mathrm{~mol}^{-1}$, but $\Delta{G_{\mathrm{r}}}^{\prime 0}$ is only $-345 \mathrm{~kJ} \mathrm{~mol}^{-1}$. 
However, in discussing the effect of product concentrations that accumulate, it is important to consider means by which they can be removed from the environment of cells producing them. The hydrocarbons methane, ethane, propane, and butane may be removed in a gas phase. Henry's law constants ${ }^{24}$ for $25^{\circ} \mathrm{C}$ show that $1 \mathrm{mM}$ aqueous dissolved concentrations correspond to gas partial pressures between 0.5 and 1 bar. Hence, they should be readily removed by evaporation into the atmosphere with dissolved concentrations remaining low. For $\mathrm{H}_{2}$, the Henry's law constant is even lower, so a $1 \mathrm{mM}$ dissolved concentration is already supersaturated at atmospheric pressure ( $0.78 \mathrm{mM}$ is saturated at $1 \mathrm{bar}$ and $25^{\circ} \mathrm{C}$ ). $\mathrm{CO}_{2}$ is more soluble with $34 \mathrm{mM}$ saturation at 1 bar and $25^{\circ} \mathrm{C}$. Hence, it would need to accumulate to $34 \mathrm{mM}$ before the formation of bubbles of pure $\mathrm{CO}_{2}$ would become favored at atmospheric pressure. If the environment of a cell could easily equilibrate with the atmosphere, the low $\mathrm{CO}_{2}$ partial pressure of 0.0004 bar would make removal favorable for any free- $\mathrm{CO}_{2}$ concentration above $0.014 \mathrm{mM}$. For organisms living at much higher pressures, for example, in the deep sea, removal to a gas phase will of course become more difficult or impossible, and these compounds will accumulate like any other solute.

In the case of hexane and benzene (and other very hydrophobic products), removal is also possible by separation of a second liquid phase. The solubility of hexane at $25{ }^{\circ} \mathrm{C}$ is about $0.12 \mathrm{mM},{ }^{25}$ so it is already supersaturated at $1 \mathrm{mM}$. For benzene, the solubility is considerably higher at $22.7 \mathrm{mM}$, but separation as a liquid is still possible if it tends to accumulate above this concentration. Under high-pressure conditions, shorter chain alkanes like butane could also separate as a liquid phase, although the database offers no solubility value for this.

\section{DISCUSSION}

It must be acknowledged at the outset that the overall Gibbs energy change is only one factor that may influence the selection of metabolic end products, both in natural biochemistry and engineered organisms. The availability of pathways using possible enzyme reactions and the thermodynamics of individual steps are clearly important. ${ }^{10-16}$ Pathways must also be compatible with suitable metabolite concentrations and cofactor use $\mathrm{e}^{10-13,16}$ and avoid excessive enzyme protein requirements. ${ }^{15,16,26}$ However, comparison of the overall most thermodynamically favored products with those observed naturally can show where other factors have been dominant. Where thermodynamically strongly favored products are observed naturally, it can be seen as an experimental validation of the idea that the overall thermodynamics has had important influence.

Among all the possibilities in Tables 3 and 4, the thermodynamically most favorable (most negative $\Delta G_{\mathrm{r}}{ }^{\prime \mathrm{m}}$ ) is the formation of elemental $\mathrm{C}$ (graphite) and $\mathrm{H}_{2} \mathrm{O}$. To the best of my knowledge, no organism producing carbon as an end product of metabolism has been described. Possibly handling a product that would tend to precipitate as soon as it formed is too much of a challenge (if it did not precipitate, then the overall Gibbs energy change to a metastable state would be lower). The next most favorable option is conversion to $\mathrm{CH}_{4}$ and $\mathrm{CO}_{2}$. These are, of course, the main final products of anaerobic biological decomposition of organic matter, although I am unaware of any single organism that carries out the entire transformation from glucose. Methane formation is restricted to special organisms that can carry out the necessary biochemistry. One of the limitations in biochemical $\mathrm{CH}_{4}$ production is considered to be the difficulties of handling reduced $C_{1}$ species. Tables 3 and 4 highlight the existence of $C_{2}$ and $C_{3}$ alternatives that are not a lot worse than making $\mathrm{CH}_{4}$. Acetate, propanoate, and butanoate are there, and the formation of such acids is a standard intermediate stage in anaerobic decomposition of organic matter. $^{27}$

The production of alkanes, ethane, propane, butane, and even hexane are rather favorable, especially with $\mathrm{CO}_{2}$ as the oxidized product. The possibility of removal into a gas or separate liquid phase would also be attractive in preventing build-up of product concentrations. Alkanes with two to six carbons are not considered usual products of anaerobic metabolism, but there is evidence that they can be formed in some organisms and ecosystems. ${ }^{17,28-33}$ Because of interest as fuel products, cells have been engineered to produce alkanes, especially propane. ${ }^{33-35}$ In principle, it could be attractive for organisms to decarboxylate short-chain fatty acids to alkanes, even if only to avoid acid accumulation. However, it seems the enzymes required have not been described, and perhaps it is difficult to engineer an appropriate active site mechanism. Benzene also appears as a reasonably attractive reduced product, but there is no clear demonstration of its formation in anaerobic metabolism. Benzene or other aromatic hydrocarbons could be further interesting targets for metabolic engineering or synthetic biology.

Among alternative oxidized products, malonate is often almost as favorable as $\mathrm{CO}_{2}$ and, in the case of methanol as the reduced product, slightly preferred (Table 4). In the biochemistry of most present organisms, malonate formation would be strongly discouraged because of its action as an inhibitor of succinate dehydrogenase, but for an archaic organism deprived of alternative oxidants, it might have been a useful option. I am not aware of any natural organism producing significant amounts of malonate, but a strain has been engineered for possible commercial manufacture. ${ }^{36}$ Production of succinate is usually quite similar to malonate, rather more favorable in combination with some reduced products, rather less so with others. Succinate is a known end product of anaerobic metabolism in several organisms, and there has been extensive effort to engineer cells for use in biotechnological production. ${ }^{37-40}$ Oxalate is always less favored than malonate, but with some reduced products, they are not very different (Table 4). Production of oxalate is known in many organisms, ${ }^{41}$ and recent studies have engineered cells to produce higher amounts. $^{42,43}$ Production of hydroxyacetate (glycolate) as an oxidized product is usually less favorable than the other options in Table 4 but, sometimes, not by too much. Although it is sometimes found as a metabolite, it has not been described as a major end product from natural organisms, although strains have been engineered to produce it. ${ }^{4}$

It is notable that most of the options discussed so far are however more favorable than the formation of lactate $\left(\Delta G_{\mathrm{r}}{ }^{\prime \mathrm{m}}=\right.$ $\left.-206 \mathrm{~kJ} \mathrm{~mol}^{-1}\right)$ or ethanol $+\mathrm{CO}_{2}\left(\Delta G_{\mathrm{r}}{ }^{\prime \mathrm{m}}=-265 \mathrm{~kJ} \mathrm{~mol}^{-1}\right)$, considered to be the canonical products of anaerobic metabolism. It may be that their prominence reflects in part a focus on facultatively anaerobic cells because of their ready formation via the glycolytic pathway that integrates with oxidative metabolism. As noted (Table 1), the formation of 3hydroxypropanoate is actually slightly more thermodynamically favorable than lactate. Some natural microorganisms produce 3hydroxypropanoate, and substantial work has been done to improve production for use as an industrial process. ${ }^{19-21}$ As a single product from glucose, glutarate is rather more favorable 
than 3-hydroxypropanoate or lactate (Table 3). The formation of glutarate from glucose has not been reported from natural organisms, just in cells engineered for possible biotechnological use. $^{45-48}$

As noted above, the overall Gibbs energy change is not the only factor controlling the selection of metabolic end products. They have to be accessible by pathways of biochemically feasible reactions, and it might be difficult for natural evolution to generate a new pathway requiring a series of metabolites and enzymes very different from ones already present. The values presented here suggest that the overall thermodynamics has not been the dominant factor in the evolution of metabolism but it has had some influence on the selection of final products. These values should certainly provide an interesting perspective on natural metabolism. They also highlight some products of biotechnological interest whose formation is thermodynamically strongly favorable. Some of these have been described as targets of metabolic engineering, but others remain future challenges for this field.

\section{CONCLUSIONS}

Calculation of overall Gibbs energy changes for conversion of glucose to a wide range of possible final products offers an interesting perspective on metabolism. These values help inform our view of current natural biochemistry, its evolution, and possible constructs from synthetic biology. It appears that the overall thermodynamics has had some influence over evolutionary choices of metabolic end products but other factors are clearly also very important. A number of thermodynamically favored products are interesting targets for metabolic engineering; some are not yet explored.

\section{METHODS}

Gibbs Energies of Formation. Gibbs energies of formation were obtained using the online eQuilibrator service ${ }^{3,4}$ (http:// equilibrator.weizmann.ac.il/; used October and November 2019). Some extended methods give slightly more accurate values but are not as readily available for use. ${ }^{5,6,8,9}$ For some compounds not available in eQuilibrator, arguments are based on energies, usually in the gas phase, from the DECHEMA database of thermophysical properties (Detherm, https:// dechema.de/en/detherm.html).

The values obtained from eQuilibrator are transformed Gibbs energies using the usual biochemical convention where $\mathrm{pH}$ is specified but $\mathrm{H}^{+}$ions are not included in the reaction equation. The mathematical transformation is from Alberty $^{2}$ where the number of hydrogen atoms in a species is multiplied by the chemical potential of $\mathrm{H}^{+}$ions then subtracted from the Gibbs energy of formation. As a result, the Gibbs energy of formation for any species containing hydrogen atoms becomes more positive (or less negative) as $\mathrm{pH}$ increases by approximately 5.7 $\mathrm{kJ} \mathrm{mol}^{-1}(R T \ln 10)$ for each $\mathrm{pH}$ unit and hydrogen atom. However, much of this $\mathrm{pH}$ dependence disappears when values are combined to give the Gibbs energy change for a reaction, leaving only the expected dependence when the reaction actually consumes or produces $\mathrm{H}^{+}$ions. The Alberty transformation has the effect of making Gibbs energy equal for all ionization states of acidic or basic compounds, so they can be treated as a single pseudo-species, as normal in biochemical equations. Many carboxylic acids are considered in the present analysis and named as the anions that predominate at neutral $\mathrm{pH}$. However, they can also be treated as having the empirical formula of the undissociated species in balancing equations.

For the main analysis, Gibbs energies of formation and reaction were obtained for the $1 \mathrm{mM}$ in solution standard state with the $\mathrm{pH}$ set at 7.0. The Gibbs energies are also somewhat dependent on ionic strength, which was left at the default value of $0.1 \mathrm{M}$.

In the case of $\mathrm{CO}_{2}$, eQuilibrator offers values based on $1 \mathrm{mM}$ of the neutral dissolved molecule $\mathrm{CO}_{2}$ or a total concentration including hydrated species particularly $\mathrm{HCO}_{3}{ }^{-}$. The difference is only $5 \mathrm{~kJ} \mathrm{~mol}^{-1}$ at $\mathrm{pH} \mathrm{7,} \mathrm{negligible} \mathrm{if} \mathrm{more} \mathrm{acidic} \mathrm{but} \mathrm{grows}$ significantly if more alkaline. In terms of overall metabolic transformations, the interpretation depends on what is assumed to be the eventual fate of $\mathrm{CO}_{2}$ produced. Values given here are based on neutral dissolved $\mathrm{CO}_{2}$, which would be appropriate if loss to or equilibration with a gas phase is relevant.

Compounds Considered. The analysis attempts to include all possible $\mathrm{C}_{1}, \mathrm{C}_{2}$, and $\mathrm{C}_{3}$ compounds containing also hydrogen and/or oxygen. However, certain classes were not considered in detail because they are generally higher in energy:

(a) Compounds in which the carbon atoms are not in a chain. The $\Delta G_{\mathrm{r}}{ }^{\prime m}$ for isomerizations of dimethyl ether to ethanol and diethyl ether to 1-butanol are calculated as -42 and $-48 \mathrm{~kJ} \mathrm{~mol}^{-1}$, respectively. Similarly, for hydrolysis of methyl acetate to methanol and acetate $\Delta G_{\mathrm{r}}{ }^{\prime \mathrm{m}}=-33 \mathrm{~kJ}$ $\mathrm{mol}^{-1}$, while for ethyl acetate to ethanol and acetate, $\Delta G_{\mathrm{r}}{ }^{\prime \mathrm{m}}=-29 \mathrm{~kJ} \mathrm{~mol}^{-1}$.

(b) Compounds with a cyclopropane ring. In the gas phase, the Gibbs energy of cyclopropane is $42 \mathrm{~kJ} \mathrm{~mol}^{-1}$ higher than that of its isomer propene (Detherm). The fourmembered heterocyclic ring of oxetane $\left(\mathrm{C}_{3} \mathrm{H}_{6} \mathrm{O}\right)$ is $144 \mathrm{~kJ}$ $\mathrm{mol}^{-1}$ higher in the gas phase than in its isomer acetone.

(c) Cumulene structures with adjacent double bonds, such as ketene $\left(\mathrm{CH}_{2}=\mathrm{C}=\mathrm{O}\right)$, as they react rapidly with water by addition to give lower-energy products such as acetate.

(d) Enol and ynol structures being higher in Gibbs energy than the tautomer carbonyl compounds.

(e) Gem-diols were taken to be in hydration equilibrium with the corresponding carbonyl compounds with the latter being favored.

For some compounds not excluded on the above basis, eQuilibrator does not have an entry or does not offer a value of $\Delta G_{f}^{\prime m}$. However, they could be dismissed as being significantly higher in energy than other compounds that are related by hydration/dehydration:

(a) Ethyne (acetylene) can be hydrated to ethanal. For its hydration in the gas phase, $\Delta G_{\mathrm{f}}^{0}$ values in Detherm give a $\Delta G_{\mathrm{r}}{ }^{0}$ of $-114 \mathrm{~kJ} \mathrm{~mol}^{-1}$, so ethanal is likely to be strongly favored also in solution.

(b) Propyne can be hydrated to acetone. For its hydration in the gas phase, $\Delta G_{\mathrm{f}}^{0}$ values in Detherm give a $\Delta G_{\mathrm{r}}{ }^{0}$ of $-119 \mathrm{~kJ} \mathrm{~mol}^{-1}$, so acetone is likely to be strongly favored also in solution. The propyne isomer propadiene is marginally even less favored with a $\Delta G_{\mathrm{f}}^{0} 8 \mathrm{~kJ} \mathrm{~mol}^{-1}$ higher.

(c) 2-Propynol is an isomer of acrolein (prop-2-enal). From data in Detherm, it can be calculated that the enthalpy of combustion of 2-propynol is approximately $80 \mathrm{~kJ} \mathrm{~mol}^{-1}$ more negative than that of acrolein, so it is clearly a less favored isomer. Hence, it must be much less favored than propanoate (see Table 2). 
(d) Propynal $\left(\mathrm{C}_{3} \mathrm{H}_{2} \mathrm{O}\right)$ can have two $\mathrm{H}_{2} \mathrm{O}$ molecules added to give $\mathrm{C}_{3} \mathrm{H}_{6} \mathrm{O}_{3}$, the formula of 3-hydroxypropanoate. Addition of water to the triple bond of propynal, a probably favorable process, will give either pyruvaldehyde or malondialdehyde. As shown in Table 1, these products are considerably higher in energy than their isomer acrylate. Hence, we can assume that propynal is not a favored hydration form.

(e) Propynoate $\left(\mathrm{C}_{3} \mathrm{H}_{2} \mathrm{O}_{2}\right)$ can add water to give malonate semialdehyde or pyruvate. Addition of water to the triple bond is expected to be favorable, especially given the following enol to carbonyl isomerization. Hence, malonate semialdehyde is probably the favored hydration form here.

(f) Malonate $\left(\mathrm{C}_{3} \mathrm{H}_{4} \mathrm{O}_{4}\right)$ may be formally dehydrated to $\mathrm{C}_{3} \mathrm{H}_{2} \mathrm{O}_{3}$ (OHC.CO.CHO or the four-membered cyclic malonic anhydride) and $\mathrm{C}_{3} \mathrm{O}_{2}$ (carbon suboxide). From enthalpies of formation in Detherm, we calculate for the reaction $\mathrm{C}_{3} \mathrm{O}_{2}(\mathrm{~g})+2 \mathrm{H}_{2} \mathrm{O}(\mathrm{l}) \rightarrow \mathrm{C}_{3} \mathrm{H}_{4} \mathrm{O}_{4}$ (malonic acid, solid), $\Delta H^{0}=-226 \mathrm{~kJ} \mathrm{~mol}^{-1}$. Thus, it seems likely that this overall hydration is strongly favored in aqueous solution. For the intermediate tricarbonyl compound, the unfavorable dehydration of hydroxyacetate to glyoxal (Table 2) shows some analogy, and acid anhydride formation will not be favored in aqueous solution, even without taking into account the strain in the ring. On similar grounds, we can rule out dehydration of $\mathrm{C}_{3} \mathrm{H}_{4} \mathrm{O}_{5}$ (hydroxymalonate) to $\mathrm{C}_{3} \mathrm{H}_{2} \mathrm{O}_{4}$ (OHC. $\mathrm{CO} \cdot \mathrm{COOH}$ or a cyclic anhydride) or $\mathrm{C}_{3} \mathrm{H}_{2} \mathrm{O}_{5}$ (oxomalonate, HOOC.CO. $\mathrm{COOH})$ to a cyclic anhydride.

Overall Transformations. Glucose can be converted to two products, one more oxidized and one more reduced. In this case, there is only one overall stoichiometric equation that produces the two products, which may also involve water as an additional reactant or product. This equation has the form

$\mathrm{C}_{6} \mathrm{H}_{12} \mathrm{O}_{6}+w \mathrm{H}_{2} \mathrm{O}=a_{1}$ reduced product $+a_{2}$ oxidized product, where $w, a_{1}$, and $a_{2}$ are stoichiometric coefficients to be determined by balancing the three elements. These stoichiometric coefficients may be fractional, and $w$ may be negative, meaning water is a product. From this equation, the overall Gibbs energy change of the transformation is calculated as

$\Delta G_{\mathrm{r}}^{\prime \prime m}=a_{1} \Delta G_{f}^{\prime m}$ (reduced product) $+a_{2} \Delta G_{f}^{\prime m}$ (oxidized product $)-w \Delta G_{f}^{\prime m}\left(\mathrm{H}_{2} \mathrm{O}\right)-\Delta G_{f}^{\prime m}\left(\mathrm{C}_{6} \mathrm{H}_{12} \mathrm{O}_{6}\right)$

eQuilibrator gives $\Delta G_{f}^{\prime m}\left(\mathrm{H}_{2} \mathrm{O}\right)$ as $-158 \mathrm{~kJ} \mathrm{~mol}^{-1}$ and $\Delta G_{\mathrm{f}}{ }^{\prime m}$ $\left(\mathrm{C}_{6} \mathrm{H}_{12} \mathrm{O}_{6}\right)$ as $-447 \mathrm{~kJ} \mathrm{~mol}^{-1}$.

Examples where $w$ is negative, zero, and positive are

$\mathrm{C}_{6} \mathrm{H}_{12} \mathrm{O}_{6}=2 \mathrm{C}_{2} \mathrm{H}_{4} \mathrm{O}$ (ethanal) $+\mathrm{C}_{2} \mathrm{H}_{2} \mathrm{O}_{3}$ (glyoxylate, OHC. $\mathrm{COOH})+\mathrm{H}_{2} \mathrm{O} ; \Delta G_{\mathrm{r}}{ }^{\prime m}=-149 \mathrm{~kJ} \mathrm{~mol}^{-1}$.

$\mathrm{C}_{6} \mathrm{H}_{12} \mathrm{O}_{6}=2.4 \mathrm{CH}_{4}+1.2 \mathrm{C}_{3} \mathrm{H}_{2} \mathrm{O}_{5}$ (oxomalonate, HOOC. $\mathrm{CO} \cdot \mathrm{COOH}) ; \Delta G_{\mathrm{r}}{ }^{\prime \mathrm{m}}=-279 \mathrm{~kJ} \mathrm{~mol}^{-1}$.

$\mathrm{C}_{6} \mathrm{H}_{12} \mathrm{O}_{6}+6 / 7 \mathrm{H}_{2} \mathrm{O}=6 / 7 \mathrm{C}_{3} \mathrm{H}_{8}+24 / 7 \mathrm{CH}_{2} \mathrm{O}_{2}$ (formate); $\Delta G_{\mathrm{r}}{ }^{\prime \prime}=-275 \mathrm{~kJ} \mathrm{~mol}^{-1}$.

\section{ASSOCIATED CONTENT}

\section{(s) Supporting Information}

The Supporting Information is available free of charge at https://pubs.acs.org/doi/10.1021/acsomega.0c00790.

Complete table of end products and all data and calculations (download address given)

(PDF)

\section{AUTHOR INFORMATION}

\section{Corresponding Author}

Peter J. Halling - WestCHEM, Department of Pure \& Applied Chemistry, University of Strathclyde, Glasgow G1 1XL, U.K.; - orcid.org/0000-0001-5077-4088; Email: p.j.halling@ strath.ac.uk

Complete contact information is available at:

https://pubs.acs.org/10.1021/acsomega.0c00790

\section{Notes}

The author declares no competing financial interest.

\section{REFERENCES}

(1) Goldberg, R. N.; Tewari, Y. B.; Bhat, T. N. Thermodynamics of enzyme-catalyzed reactions-a database for quantitative biochemistry. Bioinformatics 2004, 20, 2874-2877.

(2) Alberty, R. A. Thermodynamics of Biochemical Reactions; John Wiley \& Sons: New York, 2003.

(3) Flamholz, A.; Noor, E.; Bar-Even, A.; Milo, R. eQuilibrator-the biochemical thermodynamics calculator. Nucleic Acids Res. 2011, 40, D770-D775.

(4) Noor, E.; Haraldsdóttir, H. S.; Milo, R.; Fleming, R. M. T. Consistent Estimation of Gibbs Energy Using Component Contributions. PLoS Comput. Biol. 2013, 9, No. e1003098.

(5) Hadadi, N.; Ataman, M.; Hatzimanikatis, V.; Panayiotou, C. Molecular thermodynamics of metabolism: quantum thermochemical calculations for key metabolites. Phys. Chem. Chem. Phys. 2015, 17, $10438-10453$.

(6) Du, B.; Zhang, Z.; Grubner, S.; Yurkovich, J. T.; Palsson, B. O.; Zielinski, D. C. Temperature-Dependent Estimation of Gibbs Energies Using an Updated Group-Contribution Method. Biophys. J. 2018, 114, $2691-2702$

(7) Du, B.; Zielinski, D. C.; Palsson, B. O. Estimating Metabolic Equilibrium Constants: Progress and Future Challenges. Trends Biochem. Sci. 2018, 43, 960-969.

(8) Jinich, A.; Flamholz, A.; Ren, H.; Kim, S.-J.; Sanchez-Lengeling, B.; Cotton, C. A. R.; et al. Quantum chemistry reveals thermodynamic principles of redox biochemistry. PLoS Comput. Biol. 2018, 14, No. e1006471.

(9) Jinich, A.; Sanchez-Lengeling, B.; Ren, H.; Harman, R.; AspuruGuzik, A. A Mixed Quantum Chemistry/Machine Learning Approach for the Fast and Accurate Prediction of Biochemical Redox Potentials and Its Large-Scale Application to 315000 Redox Reactions. ACS Cent. Sci. 2019, 5, 1199-1210.

(10) Ataman, M.; Hatzimanikatis, V. Heading in the right direction: thermodynamics-based network analysis and pathway engineering. Curr. Opin. Biotechnol. 2015, 36, 176-182.

(11) Asplund-Samuelsson, J.; Janasch, M.; Hudson, E. P. Thermodynamic analysis of computed pathways integrated into the metabolic networks of E. coli and Synechocystis reveals contrasting expansion potential. Metab. Eng. 2018, 45, 223-236.

(12) Averesch, N. J. H.; Martínez, V. S.; Nielsen, L. K.; Krömer, J. O. Toward Synthetic Biology Strategies for Adipic Acid Production: An in Silico Tool for Combined Thermodynamics and Stoichiometric Analysis of Metabolic Networks. ACS Synth. Biol. 2018, 7, 490-509.

(13) Du, B.; Zielinski, D. C.; Monk, J. M.; Palsson, B. O. Thermodynamic favorability and pathway yield as evolutionary tradeoffs in biosynthetic pathway choice. Proc. Natl. Acad. Sci. U. S. A. 2018, 115, 11339-11344.

(14) Dai, Z. W.; Locasale, J. W. Thermodynamic constraints on the regulation of metabolic fluxes. J. Biol. Chem. 2018, 293, 19725-19739.

(15) Pandey, V.; Hadadi, N.; Hatzimanikatis, V. Enhanced flux prediction by integrating relative expression and relative metabolite abundance into thermodynamically consistent metabolic models. PLoS Comput. Biol. 2019, 15, No. e1007036. 
(16) Ng, C. Y.; Wang, L.; Chowdhury, A.; Maranas, C. D. Pareto Optimality Explanation of the Glycolytic Alternatives in Nature. Sci. Rep. 2019, 9, 2633.

(17) Kohn, R. A.; Kim, S.-W. Using the second law of thermodynamics for enrichment and isolation of microorganisms to produce fuel alcohols or hydrocarbons. J. Theor. Biol. 2015, 382, 356-362.

(18) Straathof, A. J.J.; Bampouli, A. Potential of commodity chemicals to become bio-based according to maximum yields and petrochemical prices. Biofuels, Bioprod. Biorefin. 2017, 11, 798-810.

(19) Kumar, V.; Ashok, S.; Park, S. Recent advances in biological production of 3-hydroxypropionic acid. Biotechnol. Adv. 2013, 31, 945961.

(20) de Fouchécour, F.; Sánchez-Castañeda, A.-K.; Saulou-Bérion, C.; Spinnler, H. É. Process engineering for microbial production of 3hydroxypropionic acid. Biotechnol. Adv. 2018, 36, 1207-1222.

(21) Ji, R.-Y.; Ding, Y.; Shi, T.-Q.; Lin, L.; Huang, H.; Gao, Z.; et al. Metabolic Engineering of Yeast for the Production of 3-Hydroxypropionic Acid. Front. Microbiol. 2018, 9, 2185.

(22) Weber, A. L. Chemical constraints governing the origin of metabolism: The thermodynamic landscape of carbon group transformations under mild aqueous conditions. Origins Life Evol. Biospheres 2002, 32, 333-357.

(23) Jinich, A.; Sanchez-Lengeling, B.; Ren, H.; Goldford, J. E.; Noor, E.; Sanders, J. N.; Segre, D.; Aspuru-Guzik, A. A thermodynamic atlas of carbon redox chemical space. bioRxiv 2019, 245811.

(24) Sander, R. Henry's Law Constants. In NIST Chemistry WebBook, NIST Standard Reference Database; Linstrom, P. J.; Mallard, W. G. editors. National Institute of Standards and Technology: Gaithersburg MD, 2019, 20899.

(25) Hefter, G. T. IUPAC-NIST Solubility Database, Version 1.1. NIST Standard Reference Database 106; NIST: cited November 2015. Available from: https://srdata.nist.gov/solubility/index.aspx.

(26) Hädicke, O.; von Kamp, A.; Aydogan, T.; Klamt, S. OptMDFpathway: Identification of metabolic pathways with maximal thermodynamic driving force and its application for analyzing the endogenous $\mathrm{CO}_{2}$ fixation potential of Escherichia coli. PLoS Comput. Biol. 2018, 14, No. e1006492.

(27) Leng, L.; Yang, P.; Singh, S.; Zhuang, H.; Xu, L.; Chen, W.-H.; et al. A review on the bioenergetics of anaerobic microbial metabolism close to the thermodynamic limits and its implications for digestion applications. Bioresour. Technol. 2018, 247, 1095-1106.

(28) Hinrichs, K.-U.; Hayes, J. M.; Bach, W.; Spivack, A. J.; Hmelo, L. R.; Holm, N. G.; et al. Biological formation of ethane and propane in the deep marine subsurface. Proc. Natl. Acad. Sci. U. S. A. 2006, 103, 14684-14689.

(29) Elsgaard, L. Reductive transformation and inhibitory effect of ethylene under methanogenic conditions in peat-soil. Soil Biol. Biochem. 2013, 60, 19-22.

(30) Strobel, G. A. Bioprospecting-fuels from fungi. Biotechnol. Lett. 2015, 37, 973-982.

(31) Allen, D. Attributing Atmospheric Methane to Anthropogenic Emission Sources. Acc. Chem. Res. 2016, 49, 1344-1350.

(32) Mustafa, M. F.; Liu, Y.; Duan, Z.; Guo, H.; Xu, S.; Wang, H.; et al. Volatile compounds emission and health risk assessment during composting of organic fraction of municipal solid waste. J. Hazard. Mater. 2017, 327, 35-43.

(33) Wang, J.; Zhu, K. Microbial production of alka(e)ne biofuels. Curr. Opin. Biotechnol. 2017, 50, 11-18.

(34) Kallio, P.; Pásztor, A.; Thiel, K.; Akhtar, M. K.; Jones, P. R. An engineered pathway for the biosynthesis of renewable propane. Nat. Commun. 2014, 5, 4731.

(35) Menon, N.; Pásztor, A.; Menon, B. R. K.; Kallio, P.; Fisher, K.; Akhtar, M. K.; et al. A microbial platform for renewable propane synthesis based on a fermentative butanol pathway. Biotechnol. Biofuels 2015, 8, 61 .

(36) Dietrich, J.; Fortman, J.; Steen, E. J. Recombinant Host Cells for the Production of Malonate. US patent 9,816,114, 2017.

(37) Pateraki, C.; Patsalou, M.; Vlysidis, A.; Kopsahelis, N.; Webb, C.; Koutinas, A. A.; et al. Actinobacillus succinogenes: Advances on succinic acid production and prospects for development of integrated biorefineries. Biochem. Eng. J. 2016, 112, 285-303.

(38) Jiang, M.; Ma, J.; Wu, M.; Liu, R.; Liang, L.; Xin, F.; et al. Progress of succinic acid production from renewable resources: Metabolic and fermentative strategies. Bioresour. Technol. 2017, 245, 1710-1717.

(39) Mazière, A.; Prinsen, P.; Garcia, A.; Luque, R.; Len, C. A review of progress in (bio)catalytic routes from/to renewable succinic acid. Biofuels, Bioprod. Biorefin. 2017, 11, 908-931.

(40) Zhu, L.-W.; Tang, Y.-J. Current advances of succinate biosynthesis in metabolically engineered Escherichia coli. Biotechnol. Adv. 2017, 35, 1040-1048.

(41) Gadd, G. M. Fungal production of citric and oxalic acid: importance in metal speciation, physiology and biogeochemical processes. Adv. Microb. Physiol. 1999, 41, 47-92.

(42) Brown, K.; Harrison, J.; Bowers, K. Production of Oxalic Acid from Aspergillus niger and Whey Permeate. Water, Air, Soil Pollut. 2018, 229, 5.

(43) Xu, Y.; Shan, L.; Zhou, Y.; Xie, Z.; Ball, A. S.; Cao, W.; et al. Development of a Cre-loxP-based genetic system in Aspergillus niger ATCC1015 and its application to construction of efficient organic acidproducing cell factories. Appl. Microbiol. Biotechnol. 2019, 103, 81058114.

(44) Deng, Y.; Ma, N.; Zhu, K.; Mao, Y.; Wei, X.; Zhao, Y. Balancing the carbon flux distributions between the TCA cycle and glyoxylate shunt to produce glycolate at high yield and titer in Escherichia coli. Metab. Eng. 2018, 46, 28-34.

(45) Rohles, C. M.; Gießelmann, G.; Kohlstedt, M.; Wittmann, C.; Becker, J. Systems metabolic engineering of Corynebacterium glutamicum for the production of the carbon-5 platform chemicals 5aminovalerate and glutarate. Microb. Cell Fact. 2016, 15, 154.

(46) Zhao, M.; Li, G.; Deng, Y. Engineering Escherichia coli for Glutarate Production as the $\mathrm{C}_{5}$ Platform Backbone. Appl. Environ. Microbiol. 2018, 84, e00814-e00818.

(47) Pérez-García, F.; Jorge, J. M. P.; Dreyszas, A.; Risse, J. M.; Wendisch, V. F. Efficient Production of the Dicarboxylic Acid Glutarate by Corynebacterium glutamicum via a Novel Synthetic Pathway. Front. Microbiol. 2018, 9, 2589.

(48) Kim, H. T.; Khang, T. U.; Baritugo, K.-A.; Hyun, S. M.; Kang, K. H.; Jung, S. H.; et al. Metabolic engineering of Corynebacterium glutamicum for the production of glutaric acid, a C5 dicarboxylic acid platform chemical. Metab. Eng. 2019, 51, 99-109. 